3. Федеральный закон от 05.04.2013 N 44-Ф3 «О контрактной системе в сфере закупок товаров, работ, услуг для обеспечения государственных и муниципальных нужд» [Электронный ресурс]. Режим доступа: http://fssprus.ru/2515217/ (дата обращения: 05.02.2020).

4. Федеральный закон от 26 июля 2006 года № 135-Ф3 «О защите конкуренции» [Электронный pecypc]. - Режим доступа: http://ivo.garant.ru/\#/document/12148517/paragraph/234791:6 (дата обращения: 17.05.2021).

5. Булей Н.В. Принципы развития контрактной системы в строительстве // Современные проблемы науки и образования. 2015. № 1-1. С. 723.

6. Науразбаева А.А., Шарипова Э.А. К вопросу об административной ответственности за нарушение положений законодательства об обеспечении государственных и муниципальных нужд // Тенденции развития науки и образования. № 70-6. С. 73-76.

7. Shpinev Iu. S. Legislative initiatives in the law on public procurement // International Journal of Humanities and Natural Sciences. 2020. № 11-2 (50). C. 155-158.

8. Шарипов В.Г., Шарипова Э.А. К вопросу о правовых основах осуществления государственных и муниципальных закупок в Российской Федерации // Экономические исследования и разработки. 2020. № 3. C. 12-17.

9. Заика М.Л., Шарипова Э.А. Правовые основы служебного поведения государственных гражданских служащих и муниципальных служащих в субъектах Российской Федерации // Евразийский юридический журнал. 2020. № 11 (150). С. 119-121.

\title{
Кошелева С.А. \\ Особенности реализации договора розничной купли-продажи в условиях развития цифровых технологий: плюсы и минусы
}

Оренбургский государственный университет (Россия, Оренбург)

doi: $10.18411 / \mathrm{j}-06-2021-217$

Научный руководитель

Коноплянникова Т.В.

\section{Аннотация}

В данном научном исследовании отражены актуальность и особенности реализации договора розничной купли-продажи в сети «Интернет». В работе даётся характеристика дистанционной торговли. Проводится анализ нормативной базы, а также практики применения договора розничной купли-продажи в условиях развития цифровых технологий. В результате данного научного исследования были выделены как преимущества, так и недостатки электронной торговли.

Ключевые слова: договор, розничная купля-продажа, дистанционная торговля, цифровые технологии, "Интернет", электронная торговля.

\section{Abstract}

This scientific study reflects the relevance and features of the implementation of the contract of retail sale on the Internet. The paper describes the characteristics of distance trading. The analysis of the regulatory framework, as well as the practice of applying the contract of retail sale in the context of the development of digital technologies is carried out. As a result of this scientific study, both the advantages and disadvantages of e-commerce were highlighted.

Keywords: contract, retail purchase and sale, remote trade, digital technologies, "Internet", e-commerce.

Мы живем во времена стремительного развития цифровых технологий, в связи с чем возникает иной способ заключения договора розничной купли-продажи непосредственно в сети "Интернет", без прямого контакта с продавцом товаров. Сейчас обширно используются договоры розничной купли-продажи в интернет-магазинах. Актуальность применения подобного способа осуществления торговли определена 
большими масштабами её развития, что упоминается в проекте Минпромторга: «Стратегии развития электронной торговли в РФ до 2025 г». [3]

Дистанционная торговля - одна из форм розничной продажи товаров. Ее отличительный признак: «удаленность продавца и покупателя друг от друга в момент заключения договора» [1]

Особенность договора розничной купли-продажи в сети "Интернет" содержится в его конструкции, которая обладает специфическими чертами. Сегодня единое регулирование подобного рода сделок отсутствует, вопреки большой распространённости их применения. В отношении договоров розничной куплипродажи в сети "Интернет", как и к розничной торговле в очном формате применяются нормы ГКРФ, которые более подробно раскрываются в Постановлении Правительства РФ от 31.12.2020 N 2463 "Об утверждении Правил продажи товаров по договору розничной купли-продажи...".

В данном исследовании, проанализировав нормативную базу, а также практику применения договора розничной купли-продажи в сети "Интернет" обозначим преимущества и недостатки электронной торговли.

Сперва, начнем с анализа недостатков, и проблемных сторон заключения договора розничной купли-продажи в сети "Интернет".

1. Лишение возможности напрямую потрогать, посмотреть, померить, а также проверить как работает тот или иной товар. Таким образом, при приобретении товара дистанционным способом, знакомство происходит только после его получении, и нередки случаи, когда реальность не соответствует ожиданиям.

Согласно п.18 Постановлении Правительства РФ от 31.12.2020 N 2463: «При дистанционном способе продажи товара продавец предоставляет потребителю полную и достоверную информацию, характеризующую предлагаемый товар, посредством ее размещения на сайте или странице сайта в сети "Интернет", или в других информационных материалах. Обязанность продавца, предусмотренная пунктом 3 статьи 26.1 Закона Российской Федерации "О защите прав потребителей", признается исполненной также в случае предоставления потребителю информации с помощью электронных и иных технических средств». [2]

Как правило, интернет-магазины заинтересованы в реализации продукции и их хорошей репутации, поэтому чаще всего продают именно те вещи, которые указаны на сайтах. Однако, встречаются недобросовестные продавцы, которые реализуют продукцию, отличающуюся от той, что указана в каталоге, на сайте этой организации, или другой платформе.

2. Риск встретить мошенников. Данный недостаток может быть отражён в предоставлении недостоверной информации о товаре или не предоставление такой информации вовсе, а также в продаже некачественного товара и т.д. В Интернете достаточно много отзывов о том, что заказанные товары оказывались подделками. Прежде чем совершать ту или иную покупку в интернете, необходимо ознакомиться с отзывами о выбранном магазине и отзывами о самом товаре, чтобы получить качественную вещь. Однако бывает и такое что, интернет-магазины, "накручивают" положительные отзывы о реализуемом ими товаре с помощью специальных площадок, тем самым обманывая покупателей.

3. Проблемы с возвратом/обменом приобретенного товара. Как правило этот недостаток отражается в отсутствии указания адреса, продавца и другой необходимой для связи информации на сайте, где осуществляется их продажа. С 01.01.2021г. действуют обновленные правила продажи товаров в розницу, с использованием сети "Интернет".

Так, в соответствии с Постановлением Правительства РФ от 31.12.2020 N 2463: «Юридические лица, зарегистрированные на территории Российской Федерации и осуществляющие продажу товаров дистанционным способом на территории 
Российской Федерации, обязаны указывать полное фирменное наименование, основной государственный регистрационный номер, адрес и место нахождения, адрес электронной почты или номер телефона. Индивидуальные предприниматели, зарегистрированные на территории Российской Федерации и осуществляющие продажу товаров дистанционным способом на территории Российской Федерации, обязаны указывать фамилию, имя, отчество, основной государственный регистрационный номер, адрес электронной почты или номер телефона. Указанная информация доводится до потребителя посредством ее размещения на сайте или странице сайта в сети "Интернет", а также в программе для электронных вычислительных машин». [2]

Ранее законодатель указывал лишь на предоставление покупателю информацию об адресе продавца, о месте изготовления товара и полном фирменном наименовании организации. Сейчас обязательных данных стало чуть больше: адрес электронный почты, контактный телефон и ОГРН. Таким образом, законодатель предпринял попытку исключить недобросовестных продавцов, которые реализуя, свою продукцию, не указывали всю необходимую информацию для связи с ними в случаи реализации права покупателя на осуществление возврата или обмена товара, ненадлежащего качества.

Более того законодатель предусмотрел и то, что теперь «продавец обязан доводить до потребителя информацию о форме и способах направления претензий. В случае если такая информация продавцом не представлена, потребитель вправе направить претензию в любой форме и любым способом».[2] В прошлой редакции закона не было четких условий об этом, в связи с чем возникали споры. Рассмотрим ситуацию: покупатель отправляет претензию на электронную почту интернет-магазина о ненадлежащем качестве реализуемого им товара, а магазин никак не реагирует. Возникает вопрос: "Кто прав?" С изменениями от 01.01.2021г. у продавца появляется возможность определить в каком виде будут приниматься те или иные заявления, если покупателю что-то не понравилось, или есть брак, и он хочется либо обменять товар, либо отказаться от покупки и т.д. Конечно, до крайности доходить не получится, т.к. выходить за рамки такого понятия, как "злоупотребление правом" нельзя. Ну, например, магазин работает за границей в Китае Италии или Германии, а покупатель в Оренбурге. В таком случаи магазин не вправе указывать требование, чтобы покупатель направлял заявление на возврат или обмен лично и в письменной форме только потому, что там находится их головной офис.

Однако есть небольшой нюанс, если продавец не прописал тот или иной порядок обращения с претензиями, то у покупателя автоматически появляется право обращаться к нему в любой форме. Таким образом, покупатель имеет право, как написать смс сообщение, с требованием вернуть или обменять товар ненадлежащего качества на качественный, или направить письмо на электронную почту интернетмагазина. В случае, если магазин пропустит срок возврата, то это будет проблема только магазина и покупатель останется прав. Таким образом законодатель предоставил больше возможностей для защиты интересов как покупателей, так и продавцов товаров.

4. Право возврата невозвратных товаров. Для покупок в режиме реального времени, лично, придя в магазин существует список так называемых "невозвратных" товаров, в который входят такие товары как: ювелирные украшения, технически сложные товары, и т.д. Для осуществления покупок дистанционном способом торговли подобный список отсутствует. Так, можно вернуть любую вещь. Однако на практики возникали проблемы. С изменениями от 01.01.2021г. продавец обязан принимать некоторые товары, даже если они надлежащего качества.

В соответствии с Постановлением Правительства РФ от 31.12.2020 N 2463: «При дистанционном способе продажи товара возврат технически сложного товара бытового 
назначения, возврат транспортного средства, возврат ювелирных изделий из драгоценных металлов или драгоценных камней, а также сертифицированных ограненных драгоценных камней надлежащего качества возможен в случае, если сохранены его потребительские свойства и товарный вид, документ, подтверждающий факт и условия покупки указанных товаров. Отсутствие у потребителя документа, подтверждающего факт и условия покупки, не лишает его возможности ссылаться на другие доказательства их приобретения у этого продавца». [2]

5. Также, к минусам дистанционной торговли относятся и трудности, относящиеся к доставке, как правило это связано с её задержкой. Таким образом, покупая товар в интернет-магазине, следует брать в расчет и время, когда он придет. Ну например, при покупки какого-либо товара в подарок лучше приобрести его заранее, чтобы не попасть в просак. Сейчас многие интернет-магазины используют «трек-коды», с помощью которых, через сайт этой организации или через сайт почты, которая производит доставку, можно следить, где ваш товар находится и знать примерную дату его доставки, что, пожалуй, является плюсом и скрашивает данный минус.

6. Ну и заключительным недостатком выделим регистрацию на сайте, а точнее последующее использование интернет-магазином персональных данных клиентов для рассылки рекламы своих товаров. Для того, чтобы совершать покупки в интернет-магазинах, чаще всего нужно пройти регистрацию на его сайте или в приложении. Однако после регистрации на почту будут ежедневно приходить письма с информацией о распродажах и различных акциях, проводимых этим интернетмагазином, что может спровоцировать на совершение ненужных покупок. Конечно, в ряде случаев можно отказаться от рассылки, но все же это доставляет некие неудобства.

Теперь перейдем к положительной стороне заключения договора розничной купли-продажи в сети "Интернет" и выделим ряд преимуществ:

1. Обязанность продавца публиковать оферту, не смотря на то, на какой платформе реализуется товар: на сайте, в приложении, социальных сетях, или любой другой интернет-платформе. Также не важно и то какой товар реализует продавец. Однако есть небольшой нюанс: оферта - не всегда отдельный документ, где в шапке черным по белому написано "Оферта". Условия могут быть размещены и на странице сайта, что также будет являться офертой.

Согласно п.12 Постановления Правительства РФ от 31.12.2020 № 2463: «При дистанционном способе продажи товара продавец обязан заключить договор розничной купли-продажи с любым лицом, выразившим намерение приобрести товар на условиях оферты». [2]

Согласно п.17: «При дистанционном способе продажи товара с использованием сети продавец обязан обеспечить возможность ознакомления потребителя с офертой путем ее размещения на сайте или странице сайта в сети "Интернет" или в программе для электронных вычислительных машин, если соглашением между продавцом и владельцем агрегатора не предусмотрен иной порядок исполнения такой обязанности». [2]

Таким образом плюсом выступает то, что продавец и покупатели больше защищены. Если раньше можно было по-разному трактовать условия покупки, то теперь с изменениями от 01.01.2021г. они четко прописаны.

2. Обязанность продавца подтвердить заказ и условия покупки. Согласно Постановление Правительства РФ от 31.12.2020 № 2463: «При дистанционном способе продажи товара с использованием информационно-телекоммуникационной сети "Интернет" или программы для электронных вычислительных машин продавец предоставляет потребителю подтверждение заключения договора розничной куплипродажи на условиях оферты, которая содержит существенные условия этого договора, 
после получения продавцом сообщения потребителя о намерении заключить договор розничной купли-продажи. Указанное подтверждение должно содержать номер заказа или иной способ идентификации заказа, который позволяет потребителю получить информацию о заключенном договоре розничной купли-продажи и его условиях».[2]

В прошлой редакции закона не было никаких положений об алгоритме действий после оформления заказа. Например, оплачиваешь тот или иной товар, а в ответ тишина. С принятием новой редакции законодатель обязал продавца после заказа подтверждать, на каких условиях и что именно оформил покупатель. Однако, то, как продавец будет осуществлять это он решает самостоятельно, например, с использованием смс сообщений, или же электронной почты. Обязательным является то, чтобы в подтверждении должен был присутствовать сам факт этого, например формулировка: здравствуйте (ФИО покупателя), мы видим, что вы у нас заказали (наименование товара) и т.д.; идентификация заказа, например его номер: Ваш заказ (номер) принят.

Закрепление такой обязанности продавца, является определённой гарантией для покупателя, способ убедиться, что с покупкой все в порядке, и просто проявление внимания и заботы в отношении клиента.

3. Экономия сил и времени покупателей. С появлением возможности реализации договора розничной купли-продажи в сети "Интернет" для того, чтобы приобрести нужный вам товар, не придется обходить кучу ТЦ тратя большое количество времени на его поиски. Теперь достаточно просто вбить запрос в браузере и найти нужный интернет-магазин. Более того, на сайтах онлайн-магазинов, а также в их приложениях как правило, предусмотрен "фильтр" - поиск по различным параметрам: размер, цвет товара, стоимость, информация о стране-производителя и т.д. Многие интернет-магазины с помощью нейросетей анализируют запросы покупателей, тем самым, предлагая аналогичные или похожие вещи, которые так же могут заинтересовать их. Экономия времени выражается и в том, что покупки можно совершать в любое время, поскольку такие магазины работают в круглосуточном режиме, без перерывов на обед и выходных.

4. Большим плюсом дистанционной торговли является и то, что с её помощью найти понравившуюся вещь стало гораздо проще, чем искать её в обычных ТЦ. В интернет-магазинах реализуется широкий ассортимент товаров и можно найти товар на любой вкус и цвет. Одной из ключевых особенностей является и то, что, некоторые товары, продаются только в онлайн формате. Как пример можно привести продажу мерча (от анг. merchandise - товар) - это атрибутика (одежда, сувенирная продукция) с символикой коммерческих проектов. Сейчас большой популярности обладают мерчи музыкальных проектов и блогеров.

5. Также положительной стороной реализации договора розничной куплипродажи в сети "Интернет" является полная характеристика продукции. На сайтах интернет-магазинов представлены полные данные о товаре начиная от размеров одежды, с точными таблицами соответствия размера одежды (S, M, L, XL) в сантиметрах и габаритов иных товаров, указание материала из чего изготовлен товар, и заканчивая информацией о стране, где произведена вещь, о чем могут умолчать продавцы в обычных магазинах.

6. Экономия денежных средств покупателя. Как правило, стоимость товаров в интернет-магазинах существенно ниже, чем в обычном магазине. Так владельцам организации не надо снимать в аренду помещения и держать большой штат сотрудников, для осуществления своей предпринимательской деятельности. Еще одним плюсом интернет-магазинов является проведение различных акций и распродаж, на которых цена товаров становится еще ниже, что подкупает покупателей.

7. Способ оплаты. Возможность выбора покупателем из нескольких вариантов оплаты покупок в интернет-магазине самый удобный для него: при 
получении товара наличными, или безналичными с помощью банковской картой или электронными деньгами (QIWI Кошелёк). Встречаются интернет-магазины, где, сначала производится оплата в полном объеме, и только потом отправка товара получателю.

8. Выбор доставки. Так же, как и выбор способа оплаты у покупателя есть и право выбрать удобный для него способ доставки, используя почту, заказать курьера с доставкой товара прямо до квартиры или же самостоятельно забрать товар из офиса интернет-магазина. В последнем случае доставка будет бесплатной.

Таким образом, проанализировав нормативно-правовую базу и практику применения договора розничной купли-продажи в сети «Интернет» можно указать как преимущества, так и недостатки осуществления данного договора. Развитие цифровых технологий не стоит на месте. Реализация договора розничной купли-продажи в сети «Интернет» прочно вошла в повседневную жизнь практически каждого человека.

Торговля таким способом является очень удобной, т.к. можно, не покидая дома, места работы или учёбы приобрести тот или иной товар. Дистанционная торговля получает все большее распространение в РФ, поэтому требует дополнений и доработок нормативно-правовых актов, регламентирующих договор розничной купли-продажи.

В следствии высоких темпов развития электронной торговли законодатель улучшает нормативную базу, чему свидетельствуют изменения от 1 января 2021 года, закрепляющие правила дистанционной торговли - как стремительно развивающемуся, новому направлению в процессе реализации договора розничной купли-продажи в условиях развития цифровых технологий.

$$
* * *
$$

1. Постановление Правительства РФ от 31.12.2020 N 2463 "Об утверждении Правил продажи товаров по договору розничной купли-продажи, перечня товаров длительного пользования, на которые не распространяется требование потребителя о безвозмездном предоставлении ему товара, обладающего этими же основными потребительскими свойствами, на период ремонта или замены такого товара, и перечня непродовольственных товаров надлежащего качества, не подлежащих обмену, а также о внесении изменений в некоторые акты Правительства Российской Федерации"// КонсультантПлюс: справочная правовая система - Режим доступа http://www.consultant.ru

2. Проект «Стратегия развития электронной торговли на период до 2025г.» // [Электронный ресурс] //

https://minpromtorg.gov.ru/docs/\#!proekt_strategiya_razvitiya_elektronnoy_torgovli_v_rossiyskoy_feder acii_na_period_do_2025_goda

3. Марчук, М.А Правовое регулирование дистанционной торговли в законодательстве России и Евросоюза. // Ленинградский юридический журнал. -2013. -№4 [Электронный ресурс] // http://cyberleninka.ru/

\section{Крутских А.C. \\ Актуальные проблемы применения ст. 15.34.1 КОАП РФ в случае необоснованного отказа от заключения публичного договора страхования}

Московский государственный юридический университет им. О.Е. Кутафина

(Россия, Москва)

doi: $10.18411 / \mathrm{j}-06-2021-218$

\section{Аннотация}

В статье проведен анализ правоприменительной практики применения ст. 15.34.1 КоАП РФ, который позволил обобщить некоторые актуальные виды проблем реализации этих норм при отказе страховой организации от заключения публичного договора: организационно-правовые проблемы незнания, неисполнения правоприменительным субъектом требований действующего законодательства и 